\title{
Prediction of tailings beach slopes and tailings flow profiles
}

\author{
A.L. Li Golder Associates Ltd., Canada
}

\begin{abstract}
Thickened and paste tailings disposal can provide a viable means to conserve water and reduce the risks associated with large volumes of water stored on the surface of tailings storage facilities. Thickened tailings deposition is a fast growing technology in the mining industry for both environmental and long term economical considerations. For surface deposition, the required beach slope and the tailings rheological properties often dictate the thickening process. The tailings beach slope is a key parameter in deposition requirements, which governs the storage capacity and the footprint of tailings management facilities. Prediction of the beach slope is fundamental for the design of non-segregating tailings stacks. But the existing tailings beach predictive models are not sufficiently developed as industrial standard applications.

This paper presents a tailings deposition model and development of an analytical tool for prediction of tailings beach slopes. Dynamic profiles of tailings flows are also discussed. The mechanisms of tailings deposition and evolution of tailings beach slopes are investigated from both geotechnical and hydraulic engineering perspectives. The model is developed based on solid mechanics and fluid mechanics principles satisfying limit equilibrium conditions and energy conservation. The governing differential equations can be solved using a numerical technique and the solution scheme can readily be implemented in Fortran or other computer language. A design tool is developed using a Fortran code (BSLOPE), which takes into account rheological properties of tailings, operation parameters and site topographic conditions. The required properties of the tailings for beach slope predictions can be determined through laboratory testing and refined during operation. Case studies demonstrate that the modelling results are in agreement with field measurements. A sensitivity study was carried out to investigate the effects of the yield stress and discharge rate on the beach slope.
\end{abstract}

\section{Introduction}

In the last two decades, thickening technologies have been advanced significantly to increase efficiency and reduce cost (Jewell et al., 2002; Jewell and Fourie, 2006). Thickened and paste tailings deposition provides a state-the-art technology in tailings management for the mining and oil sands industry to meet increasing environmental and water conservation requirements. Particularly, with the recent ERCB Directive 074 (2009) regulated by Energy Resources Conservation Board, Alberta, Canada that requires a trafficable surface on the tailings foundation within 10 years for final closure, it is anticipated that the thickened tailings deposition technology will advance at a fast pace in the years to come.

Tailings deposition requirements in terms of tailings beach slopes and rheological properties often dictates the thickening process with respect to flocculant selection and the target solids content of underflows. The primary drivers for depositional slopes are the storage capacity, foot print of the tailings management facility and stability concerns due to potential liquefaction ( $\mathrm{Li}$ et al., 2009). It is crucial to accurately predict beach slopes in mine planning since a slight change (e.g. from 3 to $2 \%$ ) of the beach slope can have very significant economical and environmental impactions (Fourie and Gawu, 2010).

Thickened and/or paste tailings deposition can produce relatively homogenous deposits and uniform beach slopes. The deposition mechanism of thickened/paste tailings is significantly different from the conventional slurry tailings with low solids concentration. Tailings slurry with high solids content exhibits viscous behaviour and can flow over a long distance without particle segregation. The beach slope measured in the field obtained from the existing thickened tailings facilities typically ranges from 2 to 5\% (Robinsky, 1999; Williams et al., 2008). Paste tailings can be stacked at a beach slope greater than 5\%. Field observations indicate that thickened tailings deposition does not eliminate the concavity of beach slopes but can significantly reduce the degree of the concavity in comparison to the slope of conventional tailings deposits (Jewell and Fourie, 2006; Kam et al., 2009). 
The deposition modelling and prediction of tailings beach slopes is a challenging task for geotechnical and/or hydraulic engineers due to the complexity of the problem requiring a multi-disciplinary solution. It is challenging to formulate the problem in a way that allows the application of existing soil mechanics or fluid mechanics principles. Further research and field data are needed to assist design and operation.

This paper presents a tailings deposition modelling technique, which can capture the essential characteristics of the deposition process for non-segregating tailings and the resulting beach slopes. The governing equations developed are implemented in a Fortran code and solved numerically. The input parameters of the numerical model include rheological properties of the tailings, operation parameters and tailings basin configurations. Using the modelling technique developed different influence factors are examined to provide an insight to the beach slope profiles under different conditions.

\section{$2 \quad$ Existing beach prediction models}

The research on the fluvial fan in hydraulic engineering (Jia, 1990; Whipple et al., 1998), spread of thin layer Bingham flows in fluid mechanics (Lui and Mei, 1989; Cochard and Ancey, 2009; Yuhi and Mei, 2004), landslide debris flows (Takahashi, 1991), dam break run out flows (Mei and Yuhi, 2001; Ancey and Cochard, 2009; Hogg and Matson, 2009), open channel flow hydraulics (Chow, 1959) have provided valuable insight to tailings beach formation for tailings researchers and engineers. In fact, some tailings researchers have followed some of these theories in fluid mechanics and hydraulic engineering to develop tailings beach formation theories to predict beach slopes.

The tailings beach slope was studied firstly for conventional segregating tailings deposition, and commonly adopted beach slope prediction equations are derived from the theory of settling aggradation of alluvial channel beds and fluvial fans. Blight and Bentel (1983), following the work of Melent'ev, showed that the beach profiles could be represented by a single dimensionless master profile using a power function. The Melent'ev Master Profile suggests that for a given tailings and solid concentration, a beach profile will conform to a master profile regardless of the vertical and horizontal distances between the point of discharge and the edge of the tailings pond. Morris and Williams (1996) and Parker et al. (1998) developed a model to describe mine tailings beaches within the framework of fluvial fan hydraulics, which was further refined by Morris (2004).

However, the deposition mechanics of non-segregating tailings is different from settling aggradation in segregating tailings slurries and river flows due to its high solids content. The existing models for nonsegregating tailings beaches are briefly discussed in the following sections.

Palmer and Krizek (1987) used a two dimensional limit equilibrium approach to model a slope profile of red mud slurry deposited in a single lift in field trials. The main parameters considered in this model are the strength of the material and discharge rates. Fourie and Gawu (2010) used a similar approach to predict the tailings beach profiles developed in flume tests to capture the boundary effects from the side walls of the flume.

Fitton et al. (2006) developed a semi-empirical model based on non-Newtonian rheology theory and turbulent channel flow equations. From their work, it was found that the beach slope is governed by a channel equilibrium slope, which is a function of the rheological properties and flow parameters for turbulent non-Newtonian flows. The equilibrium channel slope is reached when there is essentially no deposition or erosion taking place in the channel. The gradient of the beach slope is expressed as a function of density, velocity, fluid consistency index and hydraulic radius, in a semi-empirical form. It was further concluded that the concavity of the beach slope is due to high flow rates, varying solids concentration and halt of mill operation based on the field observations. Pirouz et al. (2005) and Pirouz and Williams (2007) also suggest that the beach slope is governed by self formed open channel flows.

McPhail (2008) used a stream power method (an energy approach) to describe beach slope profile and achieved good agreement with flume test and field trial deposition test data. Simms (2007) and Mizani et al. (2010) used a Liu and Mei (1989) equation to describe the tailings beach profiles in lab flume tests. The Liu and Mei equation was proposed for thin layer spreading of Bingham flows based on a lubrication theory developed in the research for lava flows. 
The existing tailings beach models analyse the final deposition and/or tailings flows on the beach developed prior to the final deposition. However, the existing beach prediction theories or tools do not address the process of gradual build up of tailings deposits in layers as observed in the field. The beach profile of the final layer depends on the beach slope of the previous layer, which imposes a challenge to justify the accuracy of the predictions using models based on energy approaches and fluid mechanics alone, since the slope of the bed affects both the fluid behaviour and energy dissipation.

\section{$3 \quad$ Formation of tailings deposits - theoretical considerations for modelling}

The formation of a non-segregating tailings deposit is different from mud flow or river delta deposits since the non-segregating deposit is built up gradually layer-by-layer in contrast to single layer deposition of a mud flow or settling aggradation in fluvial sediment deposits. Therefore, a tailings beach model based on mud flow and/or river delta hydraulics would have limited success in predicting the development of the slope profile of non-segregating tailings deposits.

Field observations indicate that deposition of non-segregating tailings occurs when tailings sheet flows stop in deposition areas and deposits on the beach in thin sheets (e.g. Crowder, 2004; Pirouz et al., 2005; Fitton, 2007). The tailings discharge often forms a channel flow close to discharge locations, and the channel meanders along the flow path to deposition areas. Subsequently, the concentrated flow spreads and forms sheet flows flowing further down on the beach. Tailings channel flows with high Reynolds numbers are generally turbulent where the velocity is high and sheet flows are usually laminar with low Reynolds numbers (Pirouz et al., 2005). The channels convey tailings to deposition areas remote from the discharge point.

Due to the complexity of the problem, we need to make some simplifications and assumptions and yet still capture the essential characteristics of the tailings deposition. The deposition model proposed is based on the observations of depositional behaviour of non-segregating tailings in the laboratory and in the field. The following characteristics of tailings flows and deposition stages are the basis of the deposition model developed.

The constitutive behaviour of the viscous non-segregating flow can be simplified as Bingham flows. It is postulated that tailings are deposited through two sequences: a forward deposition and a backward deposition. The forward deposition involves:

- A non-segregating tailings discharging from a tailings pipe or spigot at a prescribed discharge rate.

- The tailings slurry flowing and spreading on the existing ground forming a thin layer of sheet flow.

- The sheet flow becoming thinner while spreading over larger areas until the flow stops due to energy dissipation, and deposition occurs when the shear stress due to gravity is balanced by the yield stress of the Bingham material.

- The continuous discharge forming a new layer of sheet flow, which flows over top of the previous sheet and deposits at the surface.

- This deposition cycle continuing until an open channel is developed due to beach erosion by the concentrated flow at the discharge point.

In the forward deposition process, sheet flow transports the tailings particles from topographically high areas to lower areas for deposition. Once the erosion channel is developed, the tailings are deposited in a reverse sequence. This involves:

- The channel flow transporting the tailings to deposition areas.

- Tailings then fanning out at the end of the channel and spreading out laterally in the form of sheet flows for deposition, or the flow is stopped by a containment structure and deposition occurs.

- With increasing thickness of the fan at the end of the open channel, the fan provides a resistance to the open channel flow, which initiates deposition at the bottom of the channel until the flow takes a new route in a different direction, where the beach elevation is lower than the current channel bed. 
Then the channel flow disappears momentarily until another channel is developed along a different flow path.

In the backward deposition sequence, the tailings are first deposited in the downstream areas of the channel, and then deposition takes place in the upstream areas at a later stage. The forward deposition and backward deposition alternate with time depending on the slope developed and the flow rate. In both cases, layer-bylayer deposition is the dominant deposition mechanism.

The tailings flow stops when the energy loss due to the friction resistance between the flow and boundaries plus the cohesion resistance within the flow reduces the velocity and momentum of the flow to zero. At the onset of the stoppage of the tailings flow, the tailings are at a quasi solid state, where stress redistribution causes deformations and reshaping of the surface profile until the shear force due to gravity and resistance from the strength of the material reach limit equilibrium within the entire body of the freshly deposited layer. Then self weight consolidation starts and strength gain takes place. Subsequently, further strength gain may develop if the freshly deposited tailings are allowed to dry and desiccate. The deposited tailings with effective stress developed due to self weight consolidation and strength gain provides foundation support for another layer of deposition on top.

Using the above simplifications, a numerical modelling technique was developed to explicitly model deposition of each layer for the entire deposition process in order to predict the final beach slope profile. The governing equations are implemented in a Fortran code BSLOPE and are solved numerically. The developed model can capture both the forward and backward deposition mechanisms. Another numerical model is also developed for gradually changing channel flows and sheet flows of Bingham materials.

The yield stress is one of the key model parameters and is allowed to vary as the tailings flow on the beach. The yield stress of tailings may decrease along the path of the tailings flow due to a decrease in solids content as a result of runoff of consolidation water and/or rainfall water flowing down the beach (Robinsky, 1978). The yield stress may also decrease due to shear thinning. The shear thinning behaviour of mine tailings is attributed to the alignment of particles and/or flocs in the flow (Boger, 2002). Yuan and Lahaie (2010) show that oil sands tailings also tend to exhibit a decrease in the yield stress along the beach during deposition tests. The decrease in yield stress along the flow path is expected to be more pronounced for inline flocculation schemes and may be negligible for tailings which have been significantly sheared due to pumping and transportation before they reach the end of the discharge pipe.

\section{$4 \quad$ Modelling of tailings flow profiles and tailings beach slopes}

\subsection{Slowly moving dynamic flow profiles - an energy approach}

A Bingham tailings flow is similar to water flow (i.e. Newtonian flow) in terms of obeying the principle of conservation of energy, which can be expressed in terms of Bernoulli's equation. However, classical open channel flow equations for Newtonian flows cannot be directly applied to non-Newtonian tailings flows. A dynamic surface profile model is proposed for slow moving tailings channel and sheet flows. The prediction equation is derived from the hydraulic theory of open channel flows using a proposed empirical equation for non-Newtonian Bingham flows.

\subsubsection{Open channel flow - Non-Newtonian}

The theory of a Newtonian flow in open channels is well established in the literature (e.g. Chow, 1959). Figure 1 presents the concept of the energy line. The total energy can be represented using Bernoulli equation:

$$
H=\frac{p}{\gamma}+z+\frac{v^{2}}{2 g}
$$

Where:

$\begin{array}{lll}H & = & \text { total head }(\mathrm{L}) . \\ p & = & \text { water pressure }\left(\mathrm{ML}^{-1} \mathrm{~T}^{-2}\right) .\end{array}$




$\begin{array}{lll}\gamma & = & \text { unit weight of the fluid }\left(\mathrm{ML}^{-2} \mathrm{~T}^{-2}\right) . \\ z & = & \text { distance above the datum plane }(\mathrm{L}) . \\ v & = & \text { velocity of the fluid }\left(\mathrm{LT}^{-1}\right) . \\ g & = & \text { acceleration of gravity }\left(\mathrm{LT}^{-2}\right) .\end{array}$

Thickened tailings flows display non-Newtonian flow behaviour since thickened tailings exhibit yielding behaviour and possess a yield stress (Boger, 2002). The yield stress, $\tau_{y}$, is the shear strength that must be exceeded before the tailings starts to flow. Once the shear stress, $\tau$, exceeds the yield stress, $\tau_{y}$, the tailings undergo viscous flow. This behaviour can be described using the Bingham constitutive equations:

$$
\begin{gathered}
\not \&=0, \text { when } \tau_{y}<\tau \\
\tau=\tau_{y}+\eta \not \& \text {, when } \tau_{y}>\tau
\end{gathered}
$$

The viscosity, $\eta$, of a fluid is defined as the ratio of the shear stress, $\tau$, to the shear rate, $\dot{\gamma}$.

The apparent cohesion of thickened tailings is contributed to the yield stress. Exceeding the yield stress for Bingham flow results in energy loss along the open channel. It is postulated that the total energy loss of a non-Newtonian flow consists of both frictional loss and cohesive loss. The proposed hydraulic model to predict the flow profile of non-Newtonian open channel flows is derived and expressed as:

$$
\frac{d y}{d x}=\frac{i-(J+k)}{1-F r^{2}}
$$

Where:

$y \quad=\quad$ flow depth $(\mathrm{L})$.

$i \quad=\quad$ slope of the channel $(=d z / d x)$.

$\mathrm{Fr} \quad=\quad$ Froude number (the ratio of the stream velocity to the wave velocity).

The frictional loss, $J$, is defined by the empirical Manning equation in a metric system:

$$
J=\frac{n^{2} v^{2}}{R^{4 / 3}}
$$

Where:

$$
\begin{array}{lll}
n & = & \text { Manning coefficient. } \\
v & = & \text { velocity }\left(\mathrm{LT}^{-1}\right) . \\
R & = & \text { hydraulic radius of the open channel }(\mathrm{L}) .
\end{array}
$$

The cohesive loss, $k$, is defined by the following:

$$
k=\frac{\tau}{\gamma y}
$$

\subsubsection{Sheet flow - non-Newtonian}

Equation (3) can be applied to describe sheet flow profiles using a large wet perimeter (a very wide open channel with a hydraulic radius $=y$ ). When the wet perimeter becomes large, the open channel flow essentially becomes a sheet flow. 


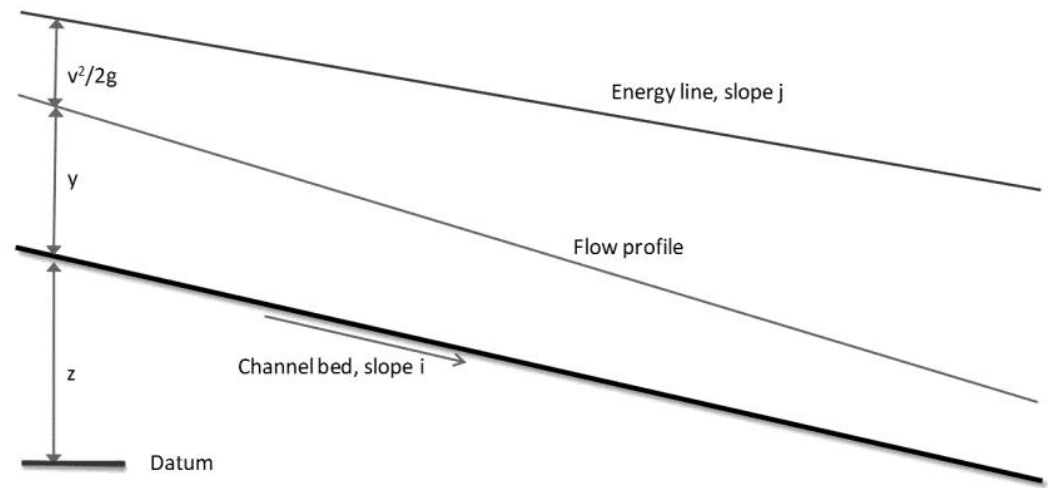

Figure 1 Open channel flow and energy diagram

\subsection{Static beach slope profile - a limit equilibrium and rheological approach}

Before sheet flow comes to a stop, the profile is governed by the principle of energy conservation. After the tailings flow stops, the tailings are in a quasi solid state, where continuum solid mechanics can be applied. The final slope profile is governed by stress redistribution and limit equilibrium. Since the thickness of sheet flows is usually thin in comparison to the width of the flow, a two-dimensional approach can be used to reduce the degrees of freedom. Two cases are considered in this paper with respect to the stoppage on inclined planes. The first case is where tailings flow downward on the beach and the second case is where the tailings stop upward against a hill (e.g. a dam face).

\subsubsection{Downhill}

We can analyse forces acting on an infinitely small element of the tailings on a deposition bed inclined at an angle of, $\theta(x)$, with a unit thickness in the perpendicular direction to the flow. Figure 2 shows a force and pressure diagram of the quasi solid element within the tailings flow at the onset of the stoppage assuming zero shear forces acting on the vertical planes of the element. The element has dimensions of width, $d x$, and depth, $d$, perpendicular to the bed, at a point $\mathrm{O}$. The pressure head, $h$, of the flow at the point $\mathrm{O}$ is:

$$
h=d \cos \theta
$$

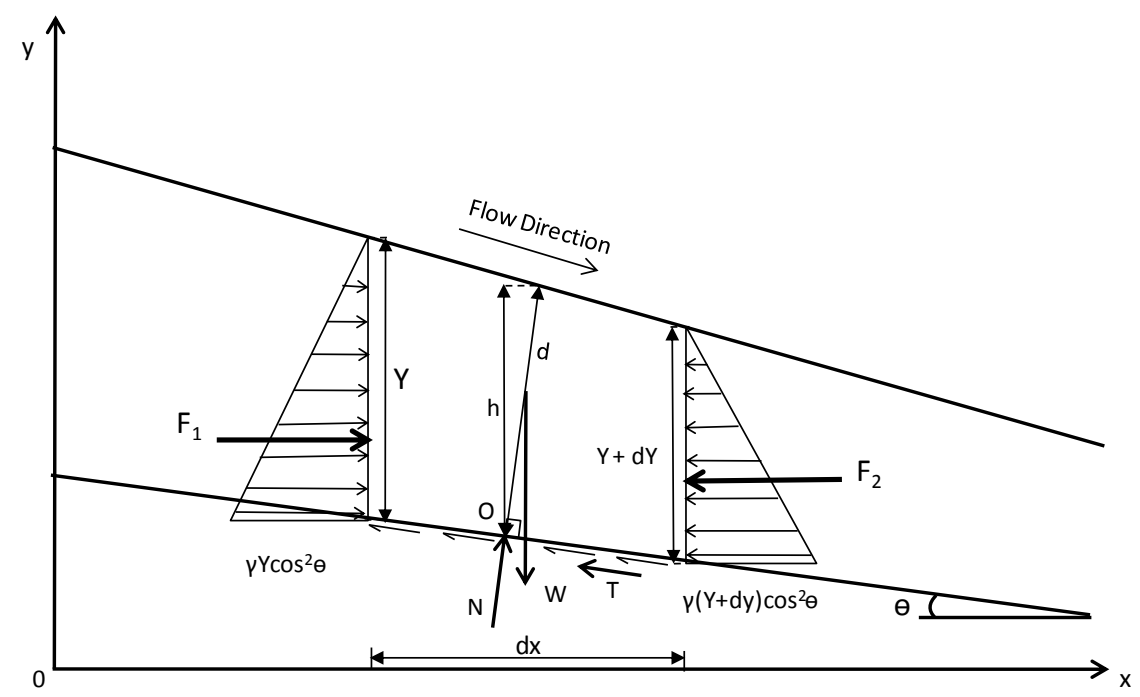

Figure 2 Force and pressure diagram of a sheet flow element in a downhill direction

At the left side, the thickness in the vertical direction is expressed as $Y$, and the thickness at the right side is $Y+d Y$. The corresponding pressure head acting on the left and right points on the bed is: 


$$
\begin{gathered}
h_{i}=Y \cos ^{2} \theta(x) \\
h_{i+1}=(Y+d y) \cos ^{2} \theta(x)
\end{gathered}
$$

The forces due to gravity are a function of unit weight and flow depths and the resistance force is a function of the yield stress $\tau_{y}(x)$. Applying force equilibrium in the horizontal and vertical directions, and neglecting the higher order differential terms, we can obtain the following equation:

$$
\frac{d Y}{d x}=\frac{\gamma Y \tan \theta(x)-\left(1+\tan ^{2} \theta(x)\right) \tau_{y}(x)}{\gamma Y \cos ^{2} \theta(x)}
$$

\subsubsection{Uphill}

Figure 3 shows the force diagram for the tailings flow stopped on an uphill slope (e.g. an uphill slope in a tailings basin).

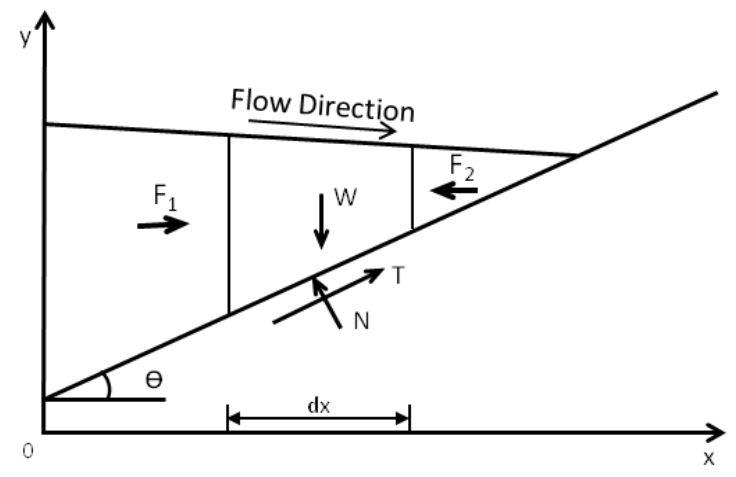

Figure 3 Force diagram for an uphill direction

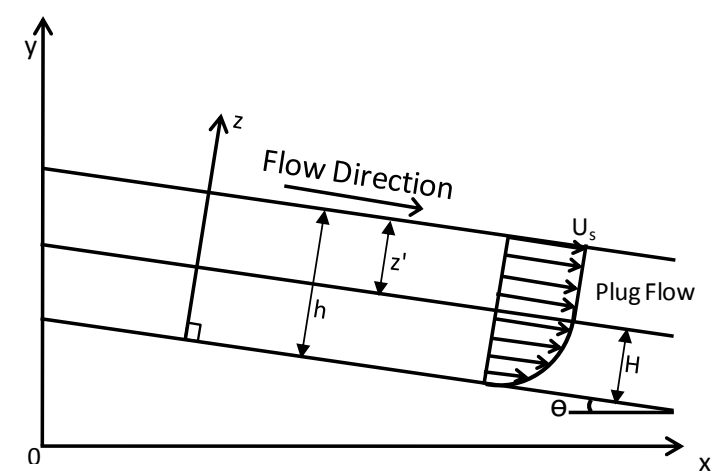

Figure 4 Bingham flow on an inclined plane

Again, neglecting the high order differential terms and substituting force equations to equilibrium equations, the governing equation for the uphill is obtained:

$$
\frac{d Y}{d x}=\frac{\left(1+\tan ^{2} \theta(x)\right) \tau_{y}(x)-\gamma Y \tan \theta(x)}{\gamma Y \cos ^{2} \theta(x)}
$$

\subsubsection{Approximation of slow spreading of Bingham flows on an inclined plane}

Figure 4 shows the regions of a Bingham flow on an inclined plane with a plug zone $z^{\prime}$, and shear zone, $H$. Slow spreading of the Bingham flow can be simplified using the following equations: 
The shear stress $\tau$ of Bingham flows is:

$$
\tau=\tau_{y}+\eta \frac{d u}{d z}
$$

Where:

$u \quad=\quad$ velocity of the flow $\left(\mathrm{LT}^{-1}\right)$.

$z \quad=\quad$ depth of the flow $(\mathrm{L})$.

The viscosity of the tailings flow dictates the velocity of the flow for a given discharge rate. Within the shear zone, $0<\mathrm{z}<\mathrm{H}$, the velocity is governed by the following equation.

$$
\begin{gathered}
\tau_{y}+\eta \frac{d u}{d z}=\gamma\left(h-z^{\prime}\right) \sin \theta \\
z^{\prime}=\frac{\tau_{y}}{\gamma \sin \theta}
\end{gathered}
$$

Where:

$z^{\prime} \quad=\quad$ plug flow thickness $(\mathrm{L})$.

The velocity of the flow is zero at the bottom and increases to the maximum at the shear plane between the plug flow and shear zone. Within the plug flow the velocity is constant and the shear rate is zero. From Equations (11) to (13), the velocity can be solved for the boundary conditions $\mathrm{z}=0$ and $\mathrm{u}=0$ and average velocity, $U_{a}$, can be obtained. The flow rate of the sheet flow is equal to the discharge rate $q$. The continuity equation can be expressed as the following approximation.

$$
q=w(x) h U_{a}
$$

Where:

$\mathrm{w}(\mathrm{x})=$ width of the sheet flow $(\mathrm{L})$.

From Equations (12) to (14), we can establish a relationship between the discharge rate and sheet flow thickness.

$$
q=w(x) h\left(\frac{1}{3}+\frac{z^{\prime}}{6 h}\right) \frac{\gamma \sin \theta}{\eta}\left(h-z^{\prime}\right)^{2}
$$

The above equation is a cubic equation with two unknown parameters, $h$ and $w(x)$. The rigorous solution for the spread of Bingham flows is mathematically complex and the governing equations are solved through a lengthy perturbation analysis (Yuhi and Mei, 2004). To simplify the prediction of the thickness for relatively thin sheet flow, we may reduce Equation (15) to the following equation to estimate the deposition thickness of sheet flows on gentle planes:

$$
h=\sqrt[3]{\frac{q \eta}{\tau}}
$$

Equations (9), (10) and (16) constitute the governing equations of the proposed tailings deposition model formulated in a general form. The relation between $h$ and $Y$ can be obtained using Cartesian coordinate transformation equations. Similar to the incremental method in the plastic theory, the differential equations can be solved numerically. The yield stress and the bed slope function may be evaluated using a piece-wise method. BSLOPE is a Fortran program that was developed to solve these equations for both the downhill deposition and uphill deposition.

The current BSLOPE Fortran code does not include the effects of self weight consolidation and desiccation with an assumption that the settlements due to self weight consolidation and desiccation will not have significant effects on the beach slope under short-term conditions. 


\section{$5 \quad$ Model features}

\subsection{Dynamic flume test flow profiles}

The dynamic flow profile predictions were calibrated using the results of flume tests on thickened copper tailings. The effect of the yield stress, the slurry density, flow rate, and bedding inclination angle on the flow profile was investigated. The results of the tests were presented elsewhere (Pornillos et al., 2009). The flume used was approximately $3.5 \mathrm{~m}$ long, $0.16 \mathrm{~m}$ wide and $0.165 \mathrm{~m}$ deep with an adjustable inclined bedding support. The flow profiles were predicted using Equation (3) and good agreement was obtained for different mobilised shear stresses, solids contents and flume slope angles. The dynamic profile prediction will be presented elsewhere in the future.

\subsection{Static flume test beach profiles}

After the discharge was stopped during the flume tests, the tailings deposited at the bottom of the flume and flow velocity became zero. A static depositional profile was obtained, which was different from the dynamic flow profile. The static depositional profile can be described using Equations (9) or (10). Also, for single layer deposition with a known bed slope, Equation (3) for dynamic flow profiles can be reduced to an equation for static profiles by reducing the discharge rate and/or velocity close to zero. Comparative analyses were carried out to predict the tailings profiles measured after the tailings flow in the flume stopped, using both the dynamic and limit equilibrium profile equations. An example of the comparative results is presented in Figure 5 for the thickened tailings with $61.7 \mathrm{wt} \%$ solids content. The mobilised yield stress was $94.8 \mathrm{~Pa}$. Also shown in Figure 5 is the profile of a sheet flow calculated using Equation (10) for the hypothetical case of an infinitely wide flume with the same discharge rate used during the flume test to simulate a sheet flow in a deposition area.

As is shown in Figure 5, all the calculated profiles using 94.8 Pa yield stress agree well with the measured profile. The calculated profiles are on top of each other, which suggest that the solutions based on energy conservation and limit equilibrium approaches are consistent.

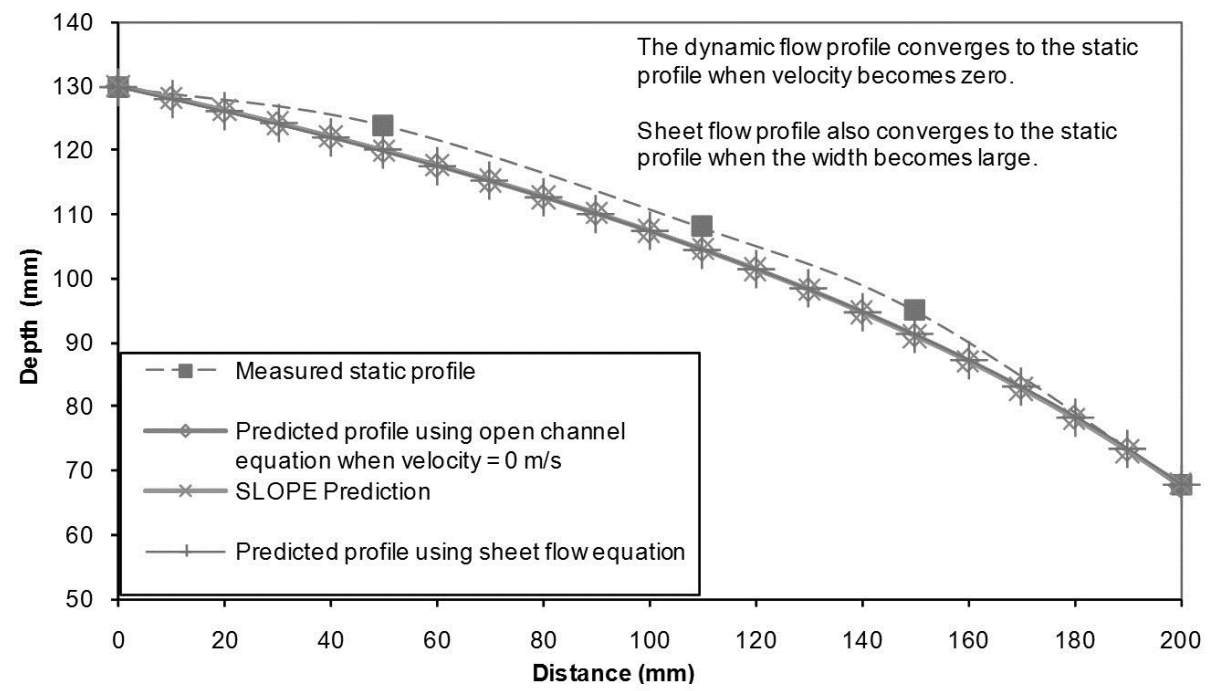

Figure 5 Calculated slope profiles and measured equilibrium slope profile

\subsection{Depositional slope profiles}

\subsubsection{Single layer deposition}

Single layer deposition through continuous discharge of tailings with a controlled tailings volume is often used to investigate the flow behaviour and beach slope characteristics. The equilibrium profile of a single layer of thickened and/or paste tailings exhibits convexity at the front of the flow when it comes to a stop. The proposed model can capture the convex shape at the front of the flow as shown in Figure 6a. 
Figure 6a illustrates another phenomenon for tailings deposition on an inclined plane, where thickness $d_{c}=\tau / \gamma \sin \theta$ represents the critical thickness of the tailings flow. For this case, the critical thickness is $0.15 \mathrm{~m}$ (normalised thickness $=1$ ) for the tailing with yield stress of 50 Pascals on a $2 \%$ slope. The dotted line represents the tailings deposited at a normalised initial thickness of 0.8 (i.e. $0.12 \mathrm{~m}$ ). The flow stops at a horizontal distance of $7.6 \mathrm{~m}$ (normalised distance $=1$ ), where the profile exhibits a convex shape. The dashed profile line is parallel to the bed when $d=d_{c}$. The solid line shows the profile where, at a normalised initial thickness of $1.2 \mathrm{~m}$ at the discharge point, the beach exhibits concavity. This behaviour of the Bingham flow partially contributes to the concavity profile in the low portion of tailings beaches.

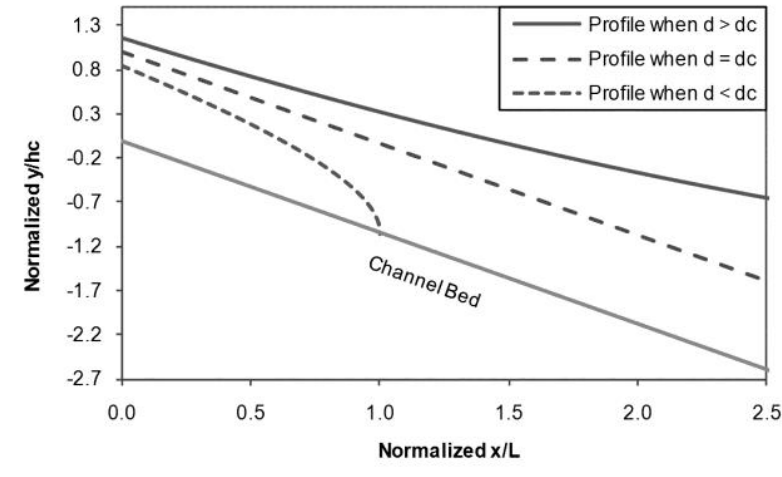

(a)

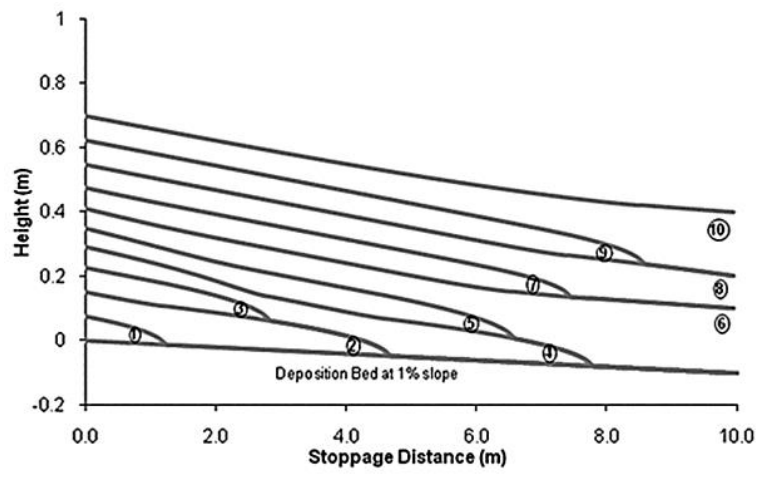

(b)

Figure 6 Evaluation of the beach slope profiles through layer-by-layer deposition modelling; (a) single layer profile, (b) multi-layer profiles

\subsubsection{Multi-layers}

As discussed earlier, a non-segregating tailings deposit is built up gradually through layer-by-layer deposition. The existing tailings beach models that only describe the final profile of tailings beaches do not take into consideration the process of a tailings deposit formed in layers. The layer-by-layer deposition is a critical aspect in tailings beach modelling as is shown in the following sections.

Figure $6 \mathrm{~b}$ shows an example of 10 layers of a tailings deposition on a $1 \%$ slope basin with a vertical containment structure $10 \mathrm{~m}$ away from the discharge point. The profiles are calculated using the proposed model for the tailings with yield stress of $50 \mathrm{~Pa}$ and discharged at a controlled rate. The first layer has a convex shape and the last layer is concave up at the end. It can be seen that the surface profile of each tailings layer is dependent on the previous tailings beach slope geometry. The shape of the profile can be convex or concave or alternating shapes along the flow direction depending on the shape of the deposition bed. It is interesting to note that the 4th layer is convex in the first section, concave in the middle section and convex again in the last section. The presence of both convex and concave shapes of a beach profile has also been observed in the laboratory and field (Fourie, 1988; Crowder, 2004). The author also observed similar beaching characteristics in small scale laboratory deposition tests with multi-layer deposition. As is shown in Figure $6 \mathrm{~b}$, the proposed model can explicitly simulate the formation of a tailings deposit and evolution of the beach profile. The model can be a powerful tool capable of capturing complex geometries of the beach and bed profiles and satisfying the governing limit equilibrium theory.

Figure 7 shows another example of BSLOPE modelling for a $34 \mathrm{~m}$ high tailings deposit built up in thin layers. The input parameters are:

Tailings properties:

- yield stress $\tau=30 \mathrm{~Pa}$

- rate of yield stress decrease with horizontal distance $r_{t}=0.02 \mathrm{~Pa} / \mathrm{m}$

- viscosity $\mu=0.03 \mathrm{~Pa} \cdot \mathrm{s}$

- unit weight $\gamma=17 \mathrm{kN} / \mathrm{m}^{3}$ 
- $\quad$ specific gravity Gs $=2.9$.

Discharge rate:

- $q=0.05 \mathrm{~m}^{3} / \mathrm{s}$.

Tailings basin:

- $\quad$ slope $i=1 \%$

- length $l=1000 \mathrm{~m}$.

Tailings dam:

- upstream slope at $2 \mathrm{H}: 1 \mathrm{~V}$

- height $H=10 \mathrm{~m}$.

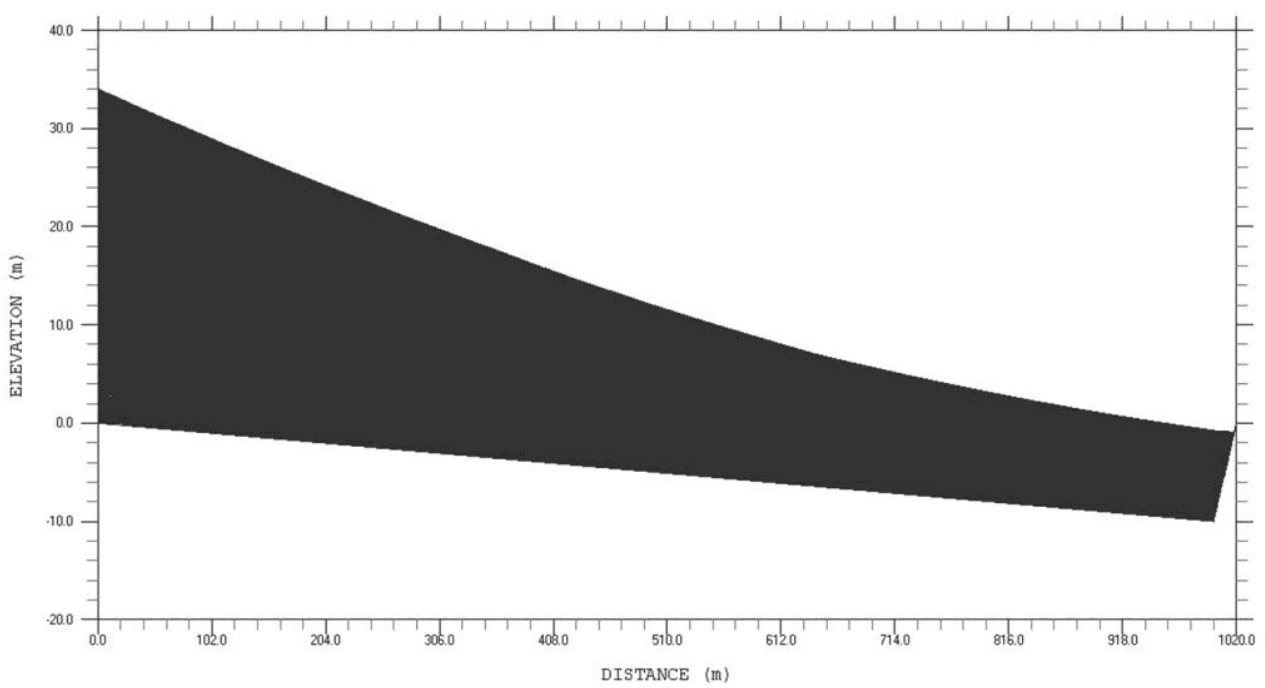

Figure 7 BSLOPE output for the formation of a tailings deposition through layer-by-layer deposition

The above figure is a plot of 1079 depositional slope profiles, where each individual line can be plotted separately for an animated demonstration to view the process of the build up of the deposit. As is shown in Figure 7, the final beach slope profile is concave up when approaching the containment dam. The maximum beach slope of $5.2 \%$ occurs at the discharge point and the slope decreases to $3.6 \%$ in the middle area and to $0.8 \%$ near the dam. An overall slope of $3.5 \%$ was achieved for this particular case.

Using the same tailings properties, a simulation of a hypothetical flume test was carried out to discharge the thickened tailings into a $3 \mathrm{~m}$ long flume inclined at $1 \%$ slope until the tailings reached the end of the flume. The overall beach slope achieved in the flume test was $6.3 \%$, which is significantly higher than the beach slope developed in the above example for a field case (3.5\%). This finding cautions the use of flume test data as pointed out by Fourie and Gawu (2010).

\section{$6 \quad$ Field predictions}

\subsection{Case 1 - Cerro de Maimon test trial}

The Cerro de Maimon Mine is located 75 km northwest of Santo Domingo in the Dominican Republic. The project involves mining and milling oxide ores and sulphide ores bearing gold, copper, silver and zinc minerals with thickened tailings and waste rock co-disposal (Wislesky and $\mathrm{Li}, 2008$ ). A series of test trials are currently underway at the mine site to investigate tailings deposition behaviour. The results of field instrumentation and observations will be discussed elsewhere in the future. 
The beach formation investigation involved discharging tailings over an existing desiccated tailings beach and monitoring the beach profiles formed at different stages. Multiple flow sheets, each 2 to $3 \mathrm{~cm}$ in thickness, formed at the end of the open flow channels on freshly deposited tailings. To determine the effect of consolidation water on the solids content along the flow path, a bulk tailings sample was obtained from a sheet flow developed at a location $208 \mathrm{~m}$ away from the discharge point. The results of moisture content indicate that the solids content decreased by $6 \%$ over the $208 \mathrm{~m}$ long flow path. Consequently, the reduction in solids content along the flow path would have resulted in a decrease in yield stress although no direct measurement of the yield stress in the field was available. Figure 8a presents the BSLOPE prediction for one of the measured sections in comparison with the field measurements. The thickened tailings had a yield stress of $12 \mathrm{~Pa}$, a unit weight $15.7 \mathrm{kN} / \mathrm{m}^{3}$, a specific gravity of 3.1 , and viscosity of approximately 0.018 $\mathrm{Pa} \cdot \mathrm{s}$. The discharge rate was $105 \mathrm{~m}^{3} / \mathrm{hr}$. For the test trial, the build up of the first $80 \mathrm{~m}$ long section of the beach could practically be measured in the field. The overall slope of the section was $2.9 \%$. Figure 8 a shows that the prediction is in good agreement with the field measurements. It is evident that the beach profile is affected by the shape of the deposition bed.

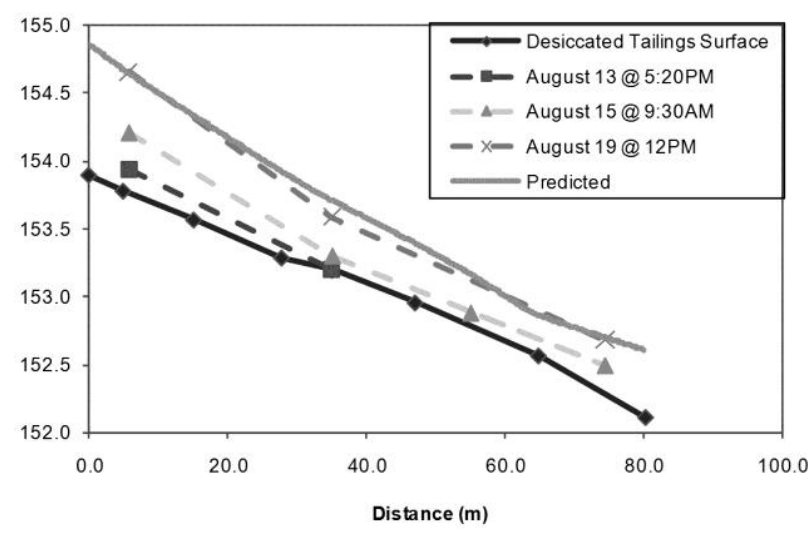

(a)

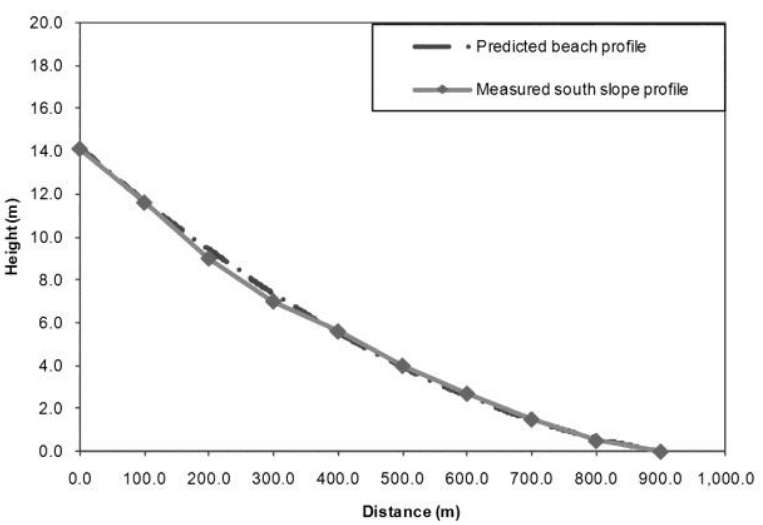

(b)

Figure 8 Beach slope profile prediction for the field cases; (a) Cerro de Maimon Mine, (b) Sunrise Dam Mine

\subsection{Case 2 - Sunrise Dam Mine}

The Sunrise Dam tailings beach is one of the most referenced studied cases for thickened tailings deposition in the literature (e.g. Fitton et al., 2006; Masterson, 2006). The studies on the Sunrise Dam tailings deposition have provided insight into the tailings beach formation. Fitton et al. (2008) obtained good agreement between the predicted profile and measured profile through detailed modelling of the localised fans to capture the concavity.

An analysis was carried out in an attempt to match the beach profile using the proposed model. Figure $8 \mathrm{~b}$ shows the back analysis for the measured beach profile that was developed up to December 2004 when the tailings deposit reached approximately $14.1 \mathrm{~m}$ at the centre of the cone. The tailings properties and operation data used in the BSLOPE analysis are based on the reported mine records and tailings properties (Fitton, 2007; Fitton et al., 2008), which are summarised as follows:

Tailings properties:

- solids content $=60 \mathrm{wt} \%$

- average yield stress $\tau=7$ Pascal

- viscosity $\mu=0.0275 \mathrm{~Pa} \cdot \mathrm{s}$

- $\quad$ specific gravity Gs $=2.8$.

Production rate:

- 301,000 tonnes per month with 5 discharge spigots. 
Tailings basin:

- $\quad$ slope $i \approx 0 \%$

- length $l=900 \mathrm{~m}$.

It is assumed that the yield stress of the tailings was $12 \mathrm{~Pa}$ at the discharge point and gradually decreased to $2 \mathrm{~Pa}$ over $900 \mathrm{~m}$ with an average of $7 \mathrm{~Pa}$ due to the decrease of solids content along the flow path.

As shown in Figure 8b, the proposed model provides an alternative approach that can accurately match the field beach slope and capture the concavity of the beach profile using the proposed modelling techniques. The upper, middle and lower portion of the beach slope were $2.4 \%, 1.5 \%$ and $0.9 \%$, respectively. In the numerical modelling, it was found that the concavity could be explained by a decrease in yield stress along the flow path and backward deposition.

\section{$7 \quad$ Beach slope influence factors}

With the proposed model, sensitivity analyses can be carried out using BSLOPE to investigate the factor influencing a particular tailings management operation. For this sensitivity study, analyses were carried out for tailings deposition on a basin with $1 \%$ slope and a $1000 \mathrm{~m}$ horizontal distance. Two non-segregating tailings examined had yield stresses of 20 and $40 \mathrm{~Pa}$, respectively, at the same decrease rate of $0.05 \mathrm{~Pa} / \mathrm{m}$ from the initial yield stress at the discharge point and with other parameters being equal. The final overall beach slope achieved was $2.7 \%$ and $4.1 \%$ for 20 and $40 \mathrm{~Pa}$, respectively. It is evident that the yield stress increases the beach slope. However, the correlation of the yield stress and beach slope is not a simple linear relationship and should be established on a case specific basis. In this case, a doubling of the yield stress increased the overall beach slope by $52 \%$.

Another significant factor is the discharge rate or the number of spigots for a particular production rate. Two simulations were carried out for the same non-segregating tailings with a yield stress of $30 \mathrm{~Pa}$ but discharged at a rate of 0.05 and $0.2 \mathrm{~m}^{3} / \mathrm{s}$, respectively. A quadrupling of the discharge rate decreased the beach slope by $41 \%$ (i.e. from $3.4 \%$ to $2.0 \%$ ) in this case.

The influence parameters in terms of other rheological properties, change in operating conditions (e.g. varying discharge rates and change in the properties due to varying ores or thickening process) can also be examined using the proposed model. The sensitivity study suggests that it is important to keep milling records and to frequently measure the rheological properties and solids content of the thickened tailings along the depositing tailings beach. The determination of the rheological properties has been discussed by Jewell and Fourie (2006).

\section{Summary and conclusions}

The formation of non-segregating tailings deposits is a highly complex dynamic process. The resulting beach slope is one of the key parameters for the design of thickened and paste deposition schemes, but it is challenging to predict. The currently available beach slope prediction models based on an energy approach, or river fan hydraulics or fluid mechanics alone appear to have severe limitations. Field observations indicate that spread and deposition of tailings in form of sheet flows is the main deposition mechanism to build up non-segregating tailings deposits. A tailings deposition modelling technique has been developed to capture this deposition mechanism with the objective to accurately predict the final beach slope.

The paper presents the salient features of the proposed tailings deposition model, which was developed based on the principles of solid mechanics and fluid mechanics. The layer-by-layer deposition is the key consideration in the modelling. The governing equations were developed in a general form allowing for varying properties, discharge rates and tailings basin slopes, and are solved numerically using a Fortran code BSLOPE. The computer model can simulate the build up of tailings deposits and evolution of beach profiles satisfying limit equilibrium conditions in the entire deposition process.

A numerical model was also developed to predict the dynamic profiles of non-Newtonian Bingham flows based on the energy conservation principle. The dynamic flow model can closely match the flume test data and warrants further investigation under field conditions. The two models were established separately using 
different theories for static slope profiles and dynamic flow profiles; however they appear to be consistent and can reach the same results when predicting the beach slope of small scale single layer deposits.

Two field cases were examined using the modelling techniques developed. The results are in good agreement with the field measurements. Furthermore, the investigation of the flow and depositional behaviour of nonsegregating tailings suggests that the factors affecting the concavity of the tailings beach include inherent Bingham flow behaviour, decrease in yield stress along flow paths due to a decrease in solids content and occurrence of backward deposition due to erosion channels associated with high discharge rates.

The proposed deposition model can accurately describe geometric features of non-segregating tailings beach slopes, and is capable of modelling varying discharge rates and varying properties of the tailings at different operating stages which is usually the case in tailings management over the mine life. The model can be applied to any topographic tailings basins since the governing equations are developed in a general form with no restrictions on the bed slope.

This paper presents an effective approach to address the complex problem of tailings deposition. The results demonstrate that it is feasible to predict the beach slope with reasonable accuracy.

\section{Acknowledgements}

The author wishes to express his thanks to D. Williams, K. Bocking, T. Eldridge, I. Wislesky, K. Been, P. Jarre, K. Shiu and J. Balins, Principals of Golder Associates, for the reviews and technical discussions, to Professor R.K. Rowe, the Vice-Principal (Research) of Queen's University, D. Becker, Principal of Golder Associates, and D. Fredlund, Professor Emeritus at the University of Saskatchewan, for the thorough reviews of the paper, to B. Andruchow for the field monitoring and organisation work at the Cerro de Maimon Mine and to N. Skomorowski for the organisation of the analysis data and figures. The author would also like to thank E. Olson of GlobeStar Mining Corp. for giving permission to publish the field data and results in the context of this paper.

\section{References}

Ancey, C. and Cochard, S. (2009) The dam-break problem for Herschel-Bulkley viscoplastic fluids down steep flumes, Journal of Non-Newtonian Fluid Mechanics, Vol. 158, pp. 18-35.

Blight, G.E. and Bentel, M.G. (1983) The behaviour of mine tailings during hydraulic deposition, Journal of the South African Institute of Mining and Metallurgy, pp. 73-86.

Boger, D. (2002) Rheological Concepts, in Paste and Thickened Tailings - A Guide, R.J. Jewell, A.B. Fourie and E.R. Lord (eds), Australian Centre for Geomechanics, Perth, Chapter 3.

Chow, V.T. (1959) Open-channel hydraulic, McGraw-Hill, 680 p.

Cochard, S. and Ancey, C. (2009) Experimental investigation of the spreading of viscoplastic fluids on inclined planes, Journal of Non-Newtonian Fluid Mechanics, Vol. 158, pp. 73-84.

Crowder, J.J. (2004) Deposition, consolidation, and strength of a non-plastic tailings paste for surface disposal, Ph.D. Thesis, University of Toronto.

ERCB Energy Resources Conservation Board (2009) Directive 074 - Tailings Performance Criteria and Requirements for Oil Sands Mining Schemes.

Fitton, T.G. (2007) Tailings beach slope prediction, PhD thesis, School of Civil, Environmental and Chemical Engineering, RMIT University.

Fitton, T.G., Chryss, A.G. and Bhattacharya, S.N. (2006) Tailings beach slope prediction: A new rheological method, International Journal of Surface Mining, Reclamation and Environment, Vol. 20(3), pp. 181-202.

Fitton, T.G., Bhattacharya, S.N. and Chryss, A.G. (2008) Three-dimensional modeling of tailings beach shape, Computer-Aided Civil and Infrastructure Engineering, Vol. 23, pp. 31-44.

Fourie, A. (1988) Beaching and permeability of tailings, Hydraulic Fill Structures, D.J.A. Van Zyl and S.G. Vick (eds), Geotechnical Special Publication No. 21.

Fourie, A.B. and Gawu, S.K.Y. (2010) The validity of laboratory flume data for predicting beach slopes of thickened tailings deposits, in Proceedings 13th International Seminar on Paste and Thickened Tailings (Paste2010), R.J. Jewell and A.B. Fourie (eds), 3-6 May 2010, Toronto, Canada, Australian Centre for Geomechanics, Perth, pp. 241-253.

Hogg, A.J. and Matson, G.P. (2009) Slumps of viscoplastic fluids on slopes, Journal of Non-Newtonian Fluid Mechanics, Vol. 158, pp. 101-112.

Jia, Y. (1990) Minimum Froude number and the equilibrium of alluvial sand rivers, Earth Surface Processes and Landforms, Vol. 15, pp. 199-209. 
Jewell, R.J., Fourie, A.B. and Lord, E.R. (eds) (2002) Paste and Thickened Tailings - A Guide, Australian Centre for Geomechanics, Perth, 171 p.

Jewell, R.J. and Fourie, A.B. (eds) (2006) Paste and Thickened Tailings - A Guide, 2nd edition, Australian Centre for Geomechanics, Perth, 242 p.

Kam, S., Yachyshyn, D., Patterson, M. and Scott, D. (2009) Thickened tailings disposal at Xstrata Copper Canada, Kidd Metallurgical Site, in Proceedings 8th International Conference on Acid Rock Drainage, Skelleftea, Sweden, June 2009.

Li, A.L., Been, K., Ritchie, D. and Welch, D. (2009) Stability of large thickened, non-segregated tailings slopes, in Proceedings 12th International Seminar on Paste and Thickened Tailings (Paste09), R.J. Jewell, A.B. Fourie, S. Barrera, J. Wiertz (eds), 21-24 April 2009, Viña Del Mar, Chile, Gecamin Limited, Santiago, Australian Centre for Geomechanics, Perth, pp. 301-311.

Liu, K.F. and Mei, C.C. (1989) Slow spreading of a sheet of Bingham fluid on an inclined plane, Journal of Fluid Mechanics, Vol. 207, pp. 505-529.

Masterson, S. (2006) Sunrise dam, Australia, in Paste and Thickened Tailings - A Guide, 2nd edition, R.J. Jewell and A.B. Fourie (eds), Australian Centre for Geomechanics, Perth, Chapter 12 - Case Studies.

Mei, C.C. and Yuhi, M. (2001) Slow flow of a Bingham fluid in a shallow channel of finite width, Journal of Fluid Mechanics, Vol. 431, pp. 135-159.

McPhail, G. (2008) Prediction of the beach profile of high-density thickened tailings from rheological and small-scale trial deposition data, in Proceedings 11th International Seminar on Paste and Thickened Tailings (Paste08), A.B. Fourie, R.J. Jewell, P. Slatter and A. Paterson (eds), 5-9 May 2008, Kasane, Botswana, Australian Centre for Geomechanics, Perth, pp. 179-185.

Mizani, S., Simms, P. and He, L. (2010) 'Out of pipe' dewatering of thickened tailings during deposition, in Proceedings 13th International Seminar on Paste and Thickened Tailings (Paste2010), R.J. Jewell and A.B. Fourie (eds), 3-6 May 2010, Toronto, Canada, Australian Centre for Geomechanics, Perth, pp. 393-402.

Morris, P.H. (2004) Mine waste beach profile and flow resistance equations, International Journal of Surface Mining, Reclamation and Environment, Vol. 18(4), pp. 253-272.

Morris, P.H. and Williams, D.J. (1996) Prediction of mine tailings delta profiles, Transactions of the American Institute of Mining and Metallurgy, Vol. 105, A63-A68.

Palmer, B. and Krizek, R. (1987) Thickened slurry disposal method for process tailings, ASCE Geotechnical Special Publication, No. 13, pp. 728-743.

Parker, G., Paola, C., Whipple, K.X. and Mohrig, D. (1998) Alluvial fans formed by channelised fluvial and sheet flow, I: Theory, Journal of the Hydraulics Division, American Society of Civil Engineers, Vol. 124 (10), pp. 985-995.

Pirouz, B., Kavianpour, M.R. and Williams, P. (2005) Thickened tailings beach deposition - field observations and fullscale flume testing, in Proceedings Eighth International Seminar on Paste and Thickened Tailings (Paste05), R.J. Jewell and S. Barrera (eds), 20-22 April 2005, Santiago, Chile, Australian Centre for Geomechanics, Perth, pp. 53-72.

Pirouz, B. and William, M.P.A. (2007) Prediction of non-segregating thickened tailings beach slope - a new method, in Proceedings Tenth International Seminar on Paste and Thickened Tailings (Paste07), A.B. Fourie and R.J. Jewell (eds), 13-15 March 2007, Perth, Australia, Australian Centre for Geomechanics, Perth, pp. 315-327.

Pornillos, E.U, Loaza, C.C. and Cabrejos, J.A. (2009) High Density Thickened Tailings Transport by Gravity, in Proceedings 12th International Seminar on Paste and Thickened Tailings (Paste09), R.J. Jewell, A.B. Fourie, S. Barrera, J. Wiertz (eds), 21-24 April 2009, Viña Del Mar, Chile, Gecamin Limited, Santiago, Australian Centre for Geomechanics, Perth, pp. 233-242.

Robinsky, E.I. (1978) Tailings disposal by the thickened discharge method for improved economy and environmental control, in Proceedings 2nd International Tailings Symposium, Denver, Colorado, USA, May 1978, pp. 75-95.

Robinsky, E.I. (1999) Thickened Tailings Disposal in the Mining Industry, E.I. Robinsky Associates, Toronto, Canada.

Simms, P. (2007) On the relation between laboratory flume tests and deposition angles of high density tailings, in Proceedings Tenth International Seminar on Paste and Thickened Tailings (Paste07), A.B. Fourie and R.J. Jewell (eds), 13-15 March 2007, Perth, Australia, Australian Centre for Geomechanics, Perth, pp. 329-335.

Takahashi, T. (1991) Debris Flow, IAHR/AIRH Monograph, Balkema, Rotterdam, 165 p.

Whipple, K.X., Parker, G., Paola, C., and Mohrig, D. (1998) Channel dynamics, sediment transport, and the slope of alluvial fans: Experimental study, The Journal of Geology, Vol. 106, pp. 677-693.

Williams, M.P.A., Seddon, K.D. and Fitton, T.G. (2008) Surface Disposal of Paste and Thickened Tailings - A Brief History and Current Confronting Issues, in Proceedings 11th International Seminar on Paste and Thickened Tailings (Paste08), A.B. Fourie, R.J. Jewell, P. Slatter and A. Paterson (eds), 5-9 May 2008, Kasane, Botswana, Australian Centre for Geomechanics, Perth, pp. 143-164.

Wislesky, I. and Li, A.L. (2008) Innovative mine waste disposal in two distinctly different settings, in Proceedings Tailings and Mine Waste '08, Vail, Colorado, USA, 19-22 October, 2008. 
Yuan, S. and Lahaie, R. (2010) Paste and thickened tailings technology and its applicability in oil sand tailings management, in Proceedings 13th International Seminar on Paste and Thickened Tailings (Paste2010), R.J. Jewell and A.B. Fourie (eds), 3-6 May 2010, Toronto, Canada, Australian Centre for Geomechanics, Perth, pp. 437-450.

Yuhi, M. and Mei, C.C. (2004) Slow spreading of fluid mud over a conical surface, Journal of Fluid Mechanics, Vol. 519, pp. 337-358. 